\title{
POLIITICA DE DIVIDENDOS, NA PRÁTICA, É IMPORTANTE?
}

\section{Lenita Loss}

Mestranda em Contabilidade na FUCAPE - ES

E-mail: lenitaloss@bol.com.br

\author{
Alfredo Sarlo Neto \\ Mestrando em Contabilidade na FUCAPE - ES \\ E-mail: asarlo@uol.com.br
}

\section{RESUMO}

Efetuou-se uma verificação dos resultados empíricos que tratam a relevância da política de financiamento, em especial, a política de dividendos. Três enfoques foram tratados: a Hipótese da Sinalização, a Hipótese do Agenciamento e a Hipótese da Preferência Tributária e o Efeito Clientela. Nas duas primeiras abordagens pode-se traçar alguma tendência. Os administradores acreditam que os dividendos carregam sinais sobre o futuro da organização e os dividendos tendem a ser utilizados como redutores de problemas relacionados a conflitos de agência. No entanto, nas três abordagens, ainda não há evidências empíricas conclusivas, especialmente porque características próprias dos diferentes mercados podem conduzir a administração a estabelecer políticas diferenciadas.

Palavras-chave: Política de dividendos, Sinalização, Agenciamento, Efeito Clientela

\section{ABSTRACT}

This article treats the empiric results about the importance of financing policies, especially dividend policies. Three focuses were discussed: the Signalling Hypothesis, the Agency Hypothesis and the Dividend Clientele Hypothesis. Some tendency can be observed in the first two approaches. Administrators believe that dividends contain signs of organizational future and that dividends tend to be used as reducers of agency conflict problems. However, in the three approaches, there still does not exist conclusive empiric evidence, especially because the specific characteristics of different markets may lead management to establish differentiated policies.

Keywords: Dividend policy, Signalling Hypothesis, Agency Hypothesis, Dividend Clientele Hypothesis 


\section{INTRODUÇÃO}

As decisões estratégicas das companhias, em boa parte das ocasiões, têm como foco o crescimento da entidade, podendo referir-se à entrada em novos negócios, expansão da capacidade produtiva, redução de custos e outras mais.

O processo de escolha do melhor projeto para a companhia e os objetivos da administração, presume-se, estão centrados na maximização do retorno ${ }^{1}$. Para o mercado, é importante que haja uma leitura correta $^{2}$ de tais expectativas, haja vista que o valor de uma companhia é determinado não pelo que ela pode auferir em fluxos de caixa no momento atual, mas sim no futuro DAMODARAN (1999, p. 151).

No entanto, várias restrições podem influenciar no crescimento de uma companhia. Por exemplo, a adoção de uma estratégia de crescimento em vendas pode estar negativamente relacionada a fatores internos à entidade, como o recurso humano operacional empregado e o empenho dos seus gerentes. Uma das fortes limitações poderá ser a política de financiamento da companhia. Para MERIKAS; BRUTON; VOZIKIS (1993, p. 2), o crescimento determina o que a política financeira da empresa pode ser e, por seu turno, a política financeira determina o quão rápido a empresa pode crescer.

Sendo assim, a determinação do valor da empresa é influenciada não só pela sua expectativa de crescimento mas também pelos riscos envolvidos em seu financiamento. Crescimento e risco são, portanto, as bases fundamentais utilizadas por analistas na determinação do valor da empresa.

A escolha do projeto passa pela determinação de seu valor presente líquido, e as fontes de financiamento das entidades podem ser os próprios recursos por elas gerados e retidos, nova entrada de capital próprio ou uso de dívida. Neste contexto, três situações distintas poderão ocorrer: ou a entidade não possui capital para sustentar tal crescimento, ou o possui de forma suficiente ou ainda, o que a entidade possui de capital excede o que é necessário para financiar o seu crescimento.

Essas decisões sobre crescimento e financiamento partem da administração das companhias e são normalmente conhecidas como políticas de investimento e de financiamento. São também permeadas por considerações acerca do funcionamento de mercado, em termos de ambiente regulatório e informações disponíveis aos investidores, o que torna mais complexa a tarefa da administração, evidenciando a relevância do assunto em questão.

\section{O PROBLEMA E O OBJETIVO DO ESTUDO}

Proposições têm sido pronunciadas por teóricos tratando de políticas de financiamento, em particular a política de dividendos. A política de dividendos não é apenas uma decisão sobre o quanto pagar ao acionista. Ela é também uma decisão sobre o quanto ficará retido na entidade, bem como dos motivos que levaram a esta retenção.

Dentre as teorias desenvolvidas, encontra-se as de DURAND (1959, p. 653), de LINTNER (1962, p. 267-268) e de GORDON (1963, p. 272) onde, num mundo de incertezas, os investidores preferirão receber dividendos o quanto antes.

Contrariamente a estes autores, a teoria de MODIGLIANI \& MILLER (1961, p. 411-433) considera ser irrelevante, sob certas circunstâncias, a estrutura financeira que a entidade venha a utilizar para financiar os seus investimentos. Assim, o valor da empresa não pode ser alterado por meio de uma simples reorganização estrutural do financiamento, como por exemplo, alterando a política de retenção de lucros. Mais recentemente, porém, alguns pesquisadores apóiam-se na teoria de CORNELL E SHAPIRO, de $1987^{3}$, como um link para investigar as possíveis inter-relações entre decisões de investimento e de financiamento.

\footnotetext{
${ }^{1}$ Refere-se às entidades que possuem fins lucrativos.

${ }^{2}$ A forma como o mercado funciona, no aspecto informacional, é fator preponderante nesta questão.

${ }^{3}$ Esta corrente se apóia na Teoria dos Stakeholders. Stakeholders são os indivíduos ou grupos de indivíduos que necessitam da entidade para realizar suas metas pessoais e a entidade, por sua vez, também é dependente deles na condução do negócio. São os clientes, fornecedores, empregados, governos, investidores etc. A crença é que alterações na habilidade da firma em cumprir reivindicações dos stakeholders interfere nas decisões de investimento e financiamento e no valor da empresa. (HOLDER, LANGREHR \& HEXTER, 1998: 1-3).
} 
Já foram empreendidas muitas pesquisas tratando do tema em questão, particularmente a partir da década de 60, quando MODIGLIANI \& MILLER apresentaram suas proposições. Com base neste referencial, faz-se o seguinte questionamento: Tendo em vista os argumentos teóricos e os estudos empíricos desenvolvidos até então, que importância pode-se atribuir à estrutura financeira das corporações, em especial, à política de dividendos? De certa forma, é uma maneira de saber se as proposições de MODIGLIANI \& MILLER estão sendo confirmadas empiricamente.

O objetivo deste trabalho, portanto, centra-se em identificar, por meio de revisão bibliográfica, que evidências têm sido encontradas sobre o tema. Serão apresentados os argumentos teóricos e enfatizada a política de dividendos sob três enfoques encontrados com freqüência na literatura: dividendos como sinalização, problemas de agenciamento e o efeito clientela. Adicionalmente, será discutida também a possível influência de algumas características presentes nos mercados na política de dividendos. Por fim, serão apresentadas as conclusões acerca do estudo.

\section{ASPECTOS TEÓRICOS DA POLÍTICA DE DIVIDENDOS}

Até o início dos anos 60 , era muito popular a idéia de que a política financeira relativa à distribuição de dividendos influenciava o valor das ações. $\mathrm{O}$ argumento baseava-se na teoria do "pássaro na mão" de GORDON e LINTNER (GITMAN, 2001, p. 412) e focava a crença de que mais vale um dividendo na mão do que um ganho de capital incerto e, portanto, sob esta ótica, os investidores tendem a valorizar mais as ações das entidades que distribuem seus resultados. Como o preço das ações no mercado oscilam, haveria sempre a incerteza quanto ao valor atribuído a uma determinada ação cujos dividendos não foram distribuídos, isto é, estaria o valor dos dividendos não pagos contemplados no preço de mercado da ação?

O trabalho de MODIGLIANI \& MILLER de 1961 contradisse o pensamento vigente e desencadeou uma série de exames empíricos que auxiliaram no desenvolvimento das pesquisas em finanças.

O argumento de MODIGLIANI \& MILLER (1961, p. 411-433) é o de que inexiste uma estrutura financeira ótima entre capital próprio e de terceiros que vá impactar positivamente o valor das ações. Os autores apoiaram sua teoria na hipótese de mercado perfeito ${ }^{4}$, na racionalidade dos agentes do mercado e na inexistência de custos de transação. A crença é a de que nenhum investidor terá poder de influenciar o mercado comprando e vendendo ações, que os impostos e corretagens são inexistentes, e que as reações dos agentes de mercado são iguais diante dos fatos.

Partindo destas premissas, suponha que um investidor esteja diante de duas companhias com o mesmo nível de investimento mas com estrutura financeira diferenciada, uma com e a outra sem dívida. Aquela que possui somente capital próprio terá um valor mais alto por ação, dada a total participação dos sócios nos investimentos da empresa. Adicionalmente, a necessidade de um maior desembolso de capital na compra desta ação poderá torná-la menos procurada, desvalorizando-a.

Por seu turno, a companhia com participação de capital de terceiros poderá estar com seu valor superestimado, tendo em vista os menores desembolsos necessários para adquirir sua ação, afinal há capital de terceiros auxiliando no financiamento dos investimentos.

No entanto, para MODIGLIANI \& MILLER os investidores são racionais e perceberão este fato. Eles mesmos tomarão ${ }^{5}$ empréstimos para comprar as ações da companhia sem dívida. Admitindo um mesmo nível de produção, venda e lucratividade nas duas companhias, o retorno, em termos de lucro, da companhia sem dívida será maior, pois ela não possui capital de terceiros e, portanto, não incorre em despesas financeiras. Mas, como o investidor tomou empréstimos, terá de pagar os juros, o que neutraliza a vantagem comparativamente aos retornos da empresa endividada. Nesta última, o retorno dos acionistas é menor, porque já está líquido de despesas de juros.

\footnotetext{
${ }^{4}$ Condições para um mercado perfeito (ROSS, 1995: 62):

a. As transações são feitas a custo zero. Há livre acesso aos mercados financeiros.

b. Há informação disponível sobre oportunidades de tomada e concessão de empréstimos.

c. Há muitos participantes, e, nenhum deles é capaz de exercer uma influência significativa sobre os preços de mercado.

${ }^{5} \mathrm{O}$ argumento é válido se os indivíduos puderem obter empréstimo às mesmas taxas que as empresas.
} 
O ponto central nesta questão é que os investidores perceberão os preços superestimados das ações da companhia com dívidas e tomarão empréstimos para comprar ações da companhia sem dívida, restabelecendo o equilíbrio nos preços das ações das duas empresas. Com base neste argumento, MODIGLIANI \& MILLER afirmam ser irrelevante a natureza do financiamento para o valor da empresa, estando inclusa, neste contexto, a política de dividendos adotada.

Adicionalmente, a teoria de MODIGLIANI \& MILLER sugere que o custo de capital da empresa seria sempre constante, não importando que tipo de financiamento é utilizado. Mesmo que o capital de terceiros seja de menor custo, quanto maior o endividamento, maior o risco para os acionistas e, portanto, maior o retorno exigido. Assim, um eventual ganho obtido com aumento de dívida é compensado pelo aumento do custo do capital próprio.

Para MODIGLIANI \& MILLER, o que deve importar aos investidores, em termos de valorização das ações, é o aproveitamento dos projetos de valor presente líquido positivo, ou seja, a política de investimentos das entidades. Se uma entidade paga baixos dividendos hoje, pode financiar seus projetos com as retenções - neste caso, os acionistas atuais financiam - e pagar dividendos maiores em data posterior. Por outro lado, se a entidade paga mais dividendos hoje, poderá financiar seus projetos por meio da entrada de novos investidores e pagar menos dividendos aos atuais investidores em data posterior. Cada unidade monetária paga a menos na forma de dividendos representa uma unidade monetária a mais em ganho de capital, e vice-versa. O valor presente dos dividendos para os investidores atuais não muda em ambos os casos; o que muda é o momento do recebimento e a oportunidade de se estar investindo em um novo projeto. Por fim, caso a entidade possua projetos com valor presente líquido positivo, MODIGLIANI \& MILLER recomendam que a distribuição de dividendos deveria ser apenas no valor que excede ao montante necessário para financiar tais projetos (Teoria Residual).

\section{A HIPÓTESE DA SINALIZAÇÃO}

Como a decisão sobre distribuição de dividendos é uma decisão de política de financiamento tomada pela administração, o mercado a percebe como uma forma de transmitir sinais sobre o desempenho futuro da empresa. Sendo assim, num mundo real, segundo a hipótese da sinalização, alterações em políticas de dividendo tendem a influenciar no valor das ações. Mais especificamente, quando a distribuição de dividendos aumenta, o mercado tende a reagir positivamente, pois a confiança no futuro da entidade caminha na mesma direção. Por outro lado, um corte é recebido como uma má notícia acerca das expectativas futuras. Segundo a teoria de MODIGLIANI \& MILLER, a eventual reação do mercado não deve ser atribuída aos dividendos, mas ao conteúdo informacional neles contido (GITMAN, 2001, p. 411). Se a sinalização dada não for sustentável, o mercado perceberá este fato e os preços se reverterão.

A possibilidade de a administração utilizar a política de dividendos como instrumento de transferir informações sugere algumas questões de estudo, como por exemplo:

- Empiricamente, o preço das ações reage de forma positiva (negativa) frente a aumentos (diminuições) na distribuição de dividendos? Neste caso, o teste é relacionado ao poder de influência de alterações em políticas de dividendos na decisão dos investidores.

- Que comportamento futuro para os resultados (lucro ou prejuízo) tem sido verificado após uma mudança na política de dividendos? Na verdade, é uma forma de verificar se a administração usa ou não usa a política de dividendos como transmissora de sinais ao mercado e se tais sinais, no futuro, tomam parte de uma realidade.

- O mercado reage de forma diferente quanto às mudanças de dividendos efetuadas por grandes e pequenas corporações? Em outras palavras, dado que as pequenas corporações possuem menos informações públicas a seu respeito, o que se questiona é que poderá haver uma reação diferenciada do mercado de acordo com o tamanho da organização, diante de mudanças em dividendos. Teoricamente, política de dividendos carregariam uma carga de informações (sinais) maior em empresas de menor monta. Estas organizações também possuem acesso restrito a mercados de capitais, o que pode desencadear 
uma necessidade maior de retenção nos lucros para cobrir as necessidades financeiras. Resta saber se a assimetria informacional ${ }^{6}$ é reduzida pela política de dividendos.

No campo empírico, AHARONY \& SWARY (1980) estudaram o uso de dividendos como instrumentos a serem usados pela gerência para transmitir informações prospectivas ao mercado. As evidências encontradas sugerem apoio à teoria da sinalização.

BAKER, FARRELLY \& EDELMAN (1985) pesquisaram 318 gerentes financeiros com o objetivo de capturar qual era a percepção destes gerentes quanto à política de dividendos. Como resultado, constatou-se que os respondentes tinham convicção de que a política de dividendos interfere no valor de mercado da empresa. Adicionalmente, constatou-se que os gerentes de empresas mais regulamentadas, como no setor de utilidades ${ }^{7}$, não possuem as mesmas opiniões das demais empresas.

ABRUTYN \& TURNER (1990) pesquisaram os principais executivos americanos, tentando identificar que teoria (sinalização, custos de agenciamento, efeito clientela) tinha mais efeito sobre as decisões de dividendos frente aos problemas dos impostos. Como resultado, os autores concluíram que nenhuma teoria explica o comportamento de todas as empresas.

MANUEL; BROOKS; SHADLER (1993) estudaram a reação do mercado a emissões de novas ações, precedendo de perto informações sobre dividendos e lucros. O mercado reage de forma negativa a este tipo de atitude, pois entende que é um sinal de que os dividendos e, conseqüentemente, o desempenho da empresa declinarão no futuro.

CHRISTIE (1994) estudou o relacionamento entre mudanças inesperadas em dividendos e o valor do patrimônio líquido no mercado. Não foram encontradas fortes reações do mercado nos casos em que houve reduções no pagamento de dividendos.

SANT \& COWN (1994) encontraram reações negativas no preço das ações no mercado relacionadas a anúncios de omissão de dividendos. As evidências encontradas também são consistentes com a hipótese de que os gerentes omitem os dividendos porque os lucros se tornam menos previsíveis. A leitura do mercado sobre o futuro da entidade não é, portanto, favorável, sendo consistente com a hipótese de sinalização.

BROOK et al. (1998) pesquisaram se as empresas fazem uso de dividendos para sinalizar futuro incremento em fluxos de caixa. Os autores constataram que as empresas incrementam seus dividendos antes dos aumentos em fluxos de caixa, tratando-se, portanto de um sinal, o que fornece apoio à hipótese da sinalização.

BRADLEY et al. (1998) estudaram o papel da volatilidade dos fluxos de caixa esperados como determinantes da política de dividendos. Tal volatilidade poderia implicar maiores proporções de distribuição de dividendos, sendo uma forma da administração reduzir incertezas. O resultado sugere, porém, que lucros mais voláteis implicam em promessa de mais baixos dividendos, fornecendo apoio à teoria da sinalização.

BAKER \& POWELL (1999), numa atualização e extensão da pesquisa prévia efetuada por BAKER, FARRELLY \& EDELMAN em 1985, investigaram como os gerentes de 198 empresas vêem a política de dividendos. Constatou-se que os gerentes acreditam que o valor da empresa é afetado pelos dividendos; tal crença está mais fortemente relacionada ao efeito sinalização, os gerentes se preocupam com a continuidade dos dividendos e, por último e contrariamente à referida pesquisa prévia, houve pouca diferença estatisticamente significativa entre as respostas obtidas dos vários setores pesquisados, sendo eles do setor de utilidades ou não.

ZENG (2001) investigou uma amostra contemplando o período de 1984 a 1988 para averiguar quais fatores eram determinantes para a política de dividendos. Foi encontrado forte apoio à hipótese da sinalização.

Outros trabalhos também foram citados na literatura consultada ${ }^{8}$, por vezes apoiando - ASQUITH \& MULLINS (1983) - por vezes não apoiando a teoria da sinalização - DeANGELO; DeANGELO; SKINNER (1996), BENARTZI; MIEHAELY;THALER (1997).

\footnotetext{
${ }^{6}$ Existe assimetria informacional quando nem todos os investidores estão perfeitamente informados sobre as ações negociadas no mercado. Informação assimétrica possui implicações diretas para o funcionamento eficiente do mercado (VARIAN, 1994: 647).

${ }^{7}$ Normalmente empresas dos setores elétrico, saneamento, comunicações e gás.

${ }^{8}$ La Porta et al. (2000: 2).
} 
A seguir quadro resumo com as informações sintetizadas:

\begin{tabular}{|c|c|c|}
\hline Título do Artigo / Autor(es) & $\begin{array}{l}\text { Data de } \\
\text { Publicação }\end{array}$ & $\begin{array}{l}\text { Aceita (A) ou } \\
\text { Rejeita (R) a } \\
\text { Hipótese da } \\
\text { Sinalização }\end{array}$ \\
\hline $\begin{array}{l}\text { Quarterly dividend and earnings announcements and stockholders' } \\
\text { returns: an empirical analysis (Aharony \& Swary) }\end{array}$ & 1980 & (A) \\
\hline The impact of initiating dividend payments on shareholders' wealth (Asquith \& Mullins) & 1983 & (A) \\
\hline A survey of management views on dividend policy (Baker, Farrelly \& Edelman) & 1985 & (A) \\
\hline Taxes and firms' dividend policies: survey results (Abrutyn \& Turner) & 1990 & $(\mathrm{R})$ \\
\hline $\begin{array}{l}\text { Common stock price effects of security issues conditioned by current } \\
\text { earnings and dividend announcements (Manuel, Brooks \& Shadler) }\end{array}$ & 1993 & (A) \\
\hline Are dividend omissions truly the cruelest cut of all? (Christie) & 1994 & $(\mathrm{R})$ \\
\hline Do dividends signal earnings? The case of omitted dividends (Sant \& Cown) & 1994 & (A) \\
\hline $\begin{array}{l}\text { Reversal of fortune: dividend policy and the disappearance of sustained earnings } \\
\text { growth (DeAngelo; DeAngelo; Skinner) }\end{array}$ & 1996 & $(\mathrm{R})$ \\
\hline Do changes in dividends signal the future or the past? (Benartzi; Miehaely; Thaler) & 1997 & $(\mathrm{R})$ \\
\hline Do firms use dividends to signal large future cash flow increases (Brook et al.) & 1998 & (A) \\
\hline Dividend policy and cash-flow uncertainty (Bradley et al.) & 1998 & (A) \\
\hline How corporate managers view dividend policy (Baker \& Powell) & 1999 & (A) \\
\hline The determinants of dividend policy: Canadian evidence (Zeng T.) & 2001 & (A) \\
\hline
\end{tabular}

Em âmbito nacional, BRITO E RIETTI (apud SPERANZINI, 1994, p. 73) realizaram em 1981 um estudo com 60 empresas que negociavam na bolsa do Rio de Janeiro. Não foi identificada evidência significante da existência de conteúdo informacional nos dividendos. Mais adiante, SPERANZINI (1994, p. 128) estudou uma amostra proveniente da carteira teórica do índice BOVESPA no período de janeiro de 1980 a dezembro de 1989 e também não encontrou indícios de haver conteúdo informacional nos dividendos.

BUENO (2000) estudou uma amostra das ações que compõem a carteira teórica do IBOVESPA no período compreendido entre 1993 e 1999. Como uma das ferramentas utilizadas por analistas de mercado é a análise fundamentalista, o autor contrapôs a taxa de retorno dos dividendos (dividend yeld) com o retorno das ações para averiguar se o uso do dividend yeld, no caso brasileiro, tem justificativa histórica como instrumento para "bater" o mercado. Foram construídas 3 carteiras diversificadas, selecionadas de acordo com o retorno do dividendos (baixo, alto e zero). Bueno não encontrou uma associação clara entre retornos de dividendos e retorno de ações, inexistindo, também, evidências de que ações com altos retornos em dividendos possuem maiores ou menores taxas de retorno do que as demais ações (de baixo ou zero dividend yeld). Não foram encontradas, portanto, evidências de que os analistas fundamentalistas podem utilizar-se do dividend yeld como um dos instrumentos para identificar boas oportunidades no mercado. Além disso, a pesquisa de Bueno permite inferir que o preços das ações das empresas que tomam parte do IBOVESPA não é associado (ao menos com clareza) aos dividendos.

\section{A HIPÓTESE DO AGENCIAMENTO}

JENSEN \& MECKING (apud PROCIANOY, 1994, p. 12) desenvolveram o modelo da teoria da agência, partindo dos estudos iniciais de COASE. Para estes autores, a essência da firma é definida pelas relações contratuais que possui. Neste conjunto de relações, a relação de agência é o contrato em que os que delegam autoridade são denominados de 
"principais" e os que são contratados para desempenhar um objetivo específico são os denominados "agentes".

Nas corporações, essas funções são desempenhadas, respectivamente, pelos proprietários e administradores. Dada a natureza da relação estabelecida, é normal que seja permeada por conflitos de interesse.

Um dos itens conflitantes deste relacionamento entre administradores e acionistas é a política de dividendos. Como a política de dividendos é estabelecida pela administração das entidades e, por seu turno, os lucros retidos estão sob o seu controle, os acionistas cercam-se de incertezas acerca dos motivos que levam os administradores a restringirem os pagamentos de dividendos. Os acionistas querem a maximização da sua riqueza, a valorização de suas ações e os gerentes nem sempre poderão estar alinhados com estes anseios. O problema pode tomar proporções maiores para acionistas minoritários, pois, se os dividendos não Ihes forem pagos, os controladores e gerentes podem usar os valores retidos para uso pessoal ou comprometê-los com projetos improdutivos (LA PORTA et al., 2000, p. 2).

Neste sentido, a teoria da agência não fornece apoio à teoria de MODIGLIANI \& MILLER, pois, se a administração usa a política de dividendos como forma de redução de conflitos com acionistas, a política de dividendos torna-se fator relevante na determinação de quais financiamentos serão usados para os investimentos a serem efetuados pela entidade, não havendo, portanto, liberdade de escolha ou, ainda, independência entre decisões de políticas de investimento e de financiamentos. A teoria da agência também tem sido objeto de testes empíricos. Se for apurado como resultado que os conflitos de agenciamento importam para as entidades, a política de dividendos também importará, não havendo, portanto, apoio à proposição de MODIGLIANI \& MILLER.

LLOYD; JAHERA; PAGE (1985) pesquisaram o custo de agência como um fator explicativo da relação de payout e os resultados demonstraram que tanto custos de agência quanto o tamanho da empresa influenciam no payout de dividendos, sendo, portanto, relevantes.
VOGT (1994) estudou o uso do fluxo de caixa em investimentos improdutivos ao invés de sua distribuição aos acionistas. $O$ autor encontrou que o fluxo de caixa financiando o crescimento de grandes empresas, que possuem capital pulverizado e que pagam baixo payout, tende a ser improdutivo. Ao contrário, no caso das empresas menores há uma criação de valor. Assim sendo, gerentes de grandes entidades podem aumentar a eficiência de seus gastos de capital pagando altos dividendos, o que sinaliza aos acionistas que um monitoramento adicional sobre gastos de capital é desnecessário. A pesquisa de VOGT mostra que a estrutura do capital da empresa e o seu tamanho são fatores que interferem na forma como a administração estabelece sua política de dividendos, estando presente aqui questões relativas ao agenciamento.

CHRISTIE (1994), já comentado anteriormente, estudou o relacionamento entre mudanças inesperadas em dividendos e o valor do patrimônio líquido no mercado, sob a luz da hipótese da sinalização e a teoria da agência. Não foram encontradas fortes reações do mercado frente às reduções no pagamento de dividendos.

LONG, MALITZ \& SEFCIK (1994) examinaram a hipótese do uso de dividendos para transferir recursos dos emprestadores aos acionistas. Os autores não encontraram evidências neste sentido e concluíram que, neste caso, as empresas acreditam ser mais relevante a sua reputação.

DEWENTER \& WARTHER (1998) compararam a relutância em se alterar as políticas de dividendos nas empresas americanas e japonesas. O resultado demonstrou que as empresas japonesas enfrentam menos assimetria informacional e, portanto, menos conflitos de agência. Como conseqüência, as empresas japonesas são menos relutantes em alterar a política de dividendos, sendo que esta acompanha mais as variações nos lucros. As empresas americanas são mais pulverizadas, ficando mais uma vez evidenciado que a estrutura e o tamanho das empresas influenciam no tratamento que a administração dá aos acionistas, inclusive no que tange à distribuição de dividendos.

HOLDER; LANGREHR; HEXTER (1998) estudaram as relações entre decisões de investimentos $\mathrm{e}$ políticas de dividendos, utilizando as idéias sobre a 
teoria de stakeholder contidas em CORNELL \& SHAPIRO (1987). A variável dependente no estudo foi a política de dividendos, a independente foi uma proxy $y^{9}$ para o resultado líquido da influência dos stakeholders na entidade (Net Organizational Capital $-N O C$ ) e as variáveis de controle dos custos de agência foram o fluxo de caixa livre ${ }^{10}$, o nível de concentração de posse do patrimônio líquido e o nível de participação dos controladores no patrimônio líquido. Foi encontrado que empresas com capital próprio mais pulverizado possuem maior custo de agenciamento e conseqüentemente maiores payouts de dividendos. Como as empresas com mais oportunidades de investimento possuem menor fluxo de caixa livre, foi encontrado que este último relaciona-se positivamente com os payouts de dividendos, significando que empresas com maior fluxo de caixa livre possuem maior custo de agência e maiores distribuições de dividendos. Por fim, empresas mais concentradas nas mãos de controladores possuem mais baixo custo de agenciamento e menor payout. Dividendos, portanto, são influenciados pelos custos de agenciamento.
LA PORTA et al. (2000) estudaram amostras de grandes empresas pertencentes a 33 países, focando problemas de agenciamento e política de dividendos. Os autores encontraram que a qualidade da proteção legal recebida pelos acionistas e a abordagem do agenciamento são relevantes para a compreensão das políticas de dividendos nos países pesquisados. Empresas que operam em países com maior proteção a acionistas minoritários, pagam mais dividendos e, quando em crescimento, diminuem os dividendos, pois tais acionistas, legalmente protegidos, estão dispostos a esperar o retorno das oportunidades de investimento. Por outro lado, acionistas que não possuem proteção legal preferem receber dividendos, mesmo na presença de projetos com perspectivas positivas.

ZENG (2001), a exemplo da hipótese da sinalização (já citado), também investigou a questão do agenciamento, encontrando apoio a esta hipótese.

A seguir quadro resumo com as informações sintetizadas:

\begin{tabular}{|c|c|c|}
\hline Título do Artigo / Autor(es) & $\begin{array}{l}\text { Data de } \\
\text { Publicação }\end{array}$ & $\begin{array}{l}\text { Aceita (A) ou } \\
\text { Rejeita (R) a } \\
\text { Hipótese do } \\
\text { Agenciamento }\end{array}$ \\
\hline Agency and dividend payout ratios (Lloyd, Jahera \& Page) & 1989 & $(A)$ \\
\hline $\begin{array}{l}\text { The cash flow / investment relationship: evidence from } \\
\text { U.S. manufacturing firms (Vogt) }\end{array}$ & 1994 & (A) \\
\hline Are dividend omissions truly the cruelest cut of all? (Christie) & 1994 & $(\mathrm{R})$ \\
\hline $\begin{array}{l}\text { An empirical examination of dividend policy following debt issues } \\
\text { (Long; Malitz; Sefcik) }\end{array}$ & 1994 & $(\mathrm{R})$ \\
\hline $\begin{array}{l}\text { Dividends, asymmetric information, and agency conflicts: } \\
\text { evidence from a comparison of the dividend policies of japonese and } \\
\text { U.S. firms (Dewenter \& Warther) }\end{array}$ & 1998 & (A) \\
\hline $\begin{array}{l}\text { Dividend policy determinants: An investigation of the influences of } \\
\text { stakeholder theory (Holder; Langrehr; Hexter (1998) }\end{array}$ & 1998 & (A) \\
\hline Agency problems and dividend policies around the world (La Porta et al.) & 2000 & (A) \\
\hline The determinants of dividend policy: Canadian evidence (Zeng T.) & 2001 & $(\mathrm{~A})$ \\
\hline
\end{tabular}

\footnotetext{
${ }^{9}$ Por dificuldades operacionais, a variável proxy é uma variável que substitui a variável real, de natureza qualitativa - neste caso, o NOC.

${ }^{10}$ Fluxo restante após considerarem-se os fluxos necessários para financiar projetos de valor presente líquido positivo.
} 
No Brasil, CUNHA (apud SPERANZINI, 1994, p. 78-79) analisou o mercado brasileiro em relação aos problemas de agenciamento e concluiu que os investidores "desconhecem o papel dos dividendos ou não os considera eficazes para tal". PROCIANOY (1994, p. 65) estudou, no período compreendido entre 1987 e 1989, o efeito da modificação tributária sobre dividendos. Como os dividendos, diferentemente dos ganhos de capital, passaram a não ser mais tributados, esperava-se maior distribuição de resultados. $\mathrm{O}$ autor concluiu que os controladores possuem forte tendência a reter a maior parcela possível de ganhos, criando assim um conflito de agência.

\section{A HIPÓTESE DA PREFERÊNCIA TRIBUTÁRIA E O EFEITO CLIENTELA}

A teoria da preferência tributária centra-se na argumentação de que, havendo taxação de impostos de forma diferenciada sobre ganhos de capital e dividendos, os acionistas tenderão a ficar com a opção que menos encargos tributários Ihes trouxer. Dividendos serão indesejáveis se forem mais pesadamente taxados, quando comparados a ganhos de capital. Até mesmo se a taxação for igual para ambos, haverá preferência pelo não recebimento dos dividendos dado que, neste caso, tem-se o benefício da postergação do pagamento do referido imposto (BUENO, 2000, p. 49).

Assim, de acordo com esta teoria, se os dividendos forem indesejados, quanto maior o payout, menos valorizada será a ação. Encontra-se esta teoria em sentido oposto à teoria do "pássaro na mão", onde a crença é a de que quanto mais altos forem os dividendos, mais seguros se sentirão seus acionistas e, portanto, mais valorizada será a ação. Por fim, a teoria da preferência tributária também se diferencia da proposição de irrelevância dos dividendos de MODIGLIANI \& MILLER por radicalizar contra recebimentos de dividendos, se estes se apresentarem indesejados, conforme a tributação.

MODIGLIANI \& MILLER, que fundamentaram seu trabalho sob a premissa de um mercado perfeito, trataram da questão dos impostos como uma imperfeição e apresentaram o argumento do efeito clientela: "uma empresa atrai acionistas cujas preferências com relação ao pagamento e à estabilidade dos dividendos correspondem ao padrão de pagamento e a estabilidade da empresa em si" (GITMAN, 2001, p. 411). Significa dizer que no mercado há investidores que, independentemente de efeitos tributários, necessitam receber dividendos e outros não. Assim, de acordo com a política de dividendos adotada cada entidade atrairá os investidores que dela se agradarem. Se os investidores encontram ações que correspondem às suas preferências, o equilíbrio é atingido e o valor das ações não é afetado pela política de dividendos.

A hipótese de clientela de dividendos, assim como as teorias do agenciamento e da sinalização, também tem sido testada empiricamente.

LEASE et al. (1978) realizaram um estudo para determinar preferências entre investidores por dividendos. Constataram que pessoas mais idosas, pessoas não muito bem empregadas, mulheres e pequenas unidades familiares preferem altos dividendos em dinheiro. Pequena correlação foi encontrada entre os efeitos dos impostos e os objetivos de investidores.

LAKONISHOK \& VERMAELEN (1986) investigaram o volume de transações com ações próximas à data ex-dividendo ${ }^{11}$. Quando os dividendos são tributados, o volume de comercialização das ações a qual se referem aumenta próximo à data ex-dividendos. Para dividendos em ação - não tributável - o efeito é contrário. Isto mostra que, ao menos no curto prazo, os investidores se preocupam com os efeitos tributários.

CHAPLINSKY \& SEYHUN (1990) encontraram que os investidores fazem sua escolha entre dividendos e ganhos de capital levando em conta as suas condições de isenção ou adiamento de pagamento quanto à questão tributária.

ABRUTYN \& TURNER (1990) pesquisaram os principais executivos americanos tentando identificar que teoria (sinalização, custos de agenciamento, efeito clientela) tinha mais efeito sobre as decisões de dividendos frente aos problemas dos impostos. Como resultado, os autores concluíram que nenhuma teoria explica o comportamento de todas as empresas, sendo que o efeito clientela foi o que recebeu apoio mais fraco na pesquisa.

MICHAELY (1991), aproveitando-se da reforma tributária americana de 1986, analisou o efeito dos

${ }^{11}$ Data em que as ações passam a ser negociados sem dividendos (vazias). 
impostos no comportamento dos preços da ações em dias ex-dividendos, comparando os anos de 1986, 1987, 1988. A alteração tributária passou a tratar dividendos e ganho de capital igualmente. Dada esta alteração, esperava-se um comportamento diferenciado por parte dos investidores em período posterior à modificação, mas não foi encontrada nenhuma evidência do efeito das modificações tributárias nos anos pesquisados.

DHALIWAL; ERICKSON; TREZEVANT (1999) pesquisaram a hipótese de que, depois que uma empresa inicia pagamento de dividendos, a posse de seu patrimônio líquido é transferida por investidores que são mais taxados por dividendos do que por ganhos de capital para investidores em situação oposta. Evidências foram encontradas neste sentido, isto é, os impostos influenciam na decisão dos investidores.

Além da hipótese da sinalização e do agenciamento já comentados neste trabalho, ZENG (2001) investigou também o efeito clientela. As evidências apóiam fracamente esta hipótese.

A seguir quadro demonstrativo sintetizando as informações sobre efeito clientela.

\begin{tabular}{|c|c|c|}
\hline Título do Artigo / Autor(es) & $\begin{array}{c}\text { Data de } \\
\text { Publicação }\end{array}$ & $\begin{array}{c}\text { Aceita (A) ou } \\
\text { Rejeita (R) } \\
\text { o Efeito } \\
\text { Clientela }\end{array}$ \\
\hline $\begin{array}{l}\text { Some direct evidence on the dividend clientele phenomenon } \\
\text { (Lease, R. C., et al.) }\end{array}$ & 1978 & $(\mathrm{R})$ \\
\hline $\begin{array}{l}\text { Tax-induced trading around ex-dividend days } \\
\text { (Lakonishok, J. \& Vermaelen, T.) }\end{array}$ & 1986 & (A) \\
\hline $\begin{array}{l}\text { Dividend and taxes: evidence on tax-reduction strategies. } \\
\text { (Chaplinsky, S. \& Seyhun, H. N.) }\end{array}$ & 1990 & (A) \\
\hline $\begin{array}{l}\text { Taxes and firms' dividend policies: survey results } \\
\text { (Abrutyn, S. \& Turner, R. W.) }\end{array}$ & 1990 & (R) \\
\hline $\begin{array}{l}\text { Ex-dividend day stock price behavior: the case of the } 1986 \text { tax } \\
\text { reform act. (Michaely, R.) }\end{array}$ & 1991 & (R) \\
\hline $\begin{array}{l}\text { A test of the theory of tax clienteles for dividend policies } \\
\text { (Dhaliwal, D. S. et al.) }\end{array}$ & 1999 & (A) \\
\hline The determinants of dividend policy: Canadian evidence (Zeng T.) & 2001 & $(\mathrm{R})$ \\
\hline
\end{tabular}

No Brasil, BRITO E RIETTI (apud SPERANZINI, 1994, p. 76), já citados neste trabalho, acerca do estudo realizado com 60 empresas que negociavam na Bolsa de valores do Rio de Janeiro, concluíram ser inexistente o efeito clientela na amostra pesquisada. Por outro lado, no estudo de SPERANZINI (1994, p. 128), também já comentado neste artigo, constatouse que os investidores consideravam os dividendos indesejáveis e, por isso, exigiam retornos maiores para ações que pagavam dividendos. O autor atribuiu esta evidência ao fato de que, no período pesquisado, os dividendos eram taxados e os ganhos de capital não.

ABREU (2002) analisou as preposições de MODIGLIANI \& MILLER comparando a legislação tributária norte-americana e a brasileira, especialmente quanto à isenção de impostos sobre o recebimento de dividendos e quanto à tributação diferenciada dos Juros Sobre o Capital Próprio. Neste estudo, foram apresentadas, de forma matemática, as vantagens proporcionadas pela legislação tributária brasileira na determinação do valor da empresa. $O$ autor demonstrou que a legislação tributária pode afetar a preferência dos acionistas pelo recebimento ou não de dividendos.

\section{A INFLUÊNCIA DO AMBIENTE SOBRE A POLÍTICA DE DIVIDENDOS}

Os mercados de capitais existentes no mundo possuem mecanismos próprios de funcionamento. Geralmente, a forma de funcionamento está atrelada, principalmente, às legislações específicas e ao nível de desenvolvimento econômico e institucional. 
Estas condições influenciam não apenas na qualidade da informação que flui nestes mercados mas também no acesso aos recursos disponíveis. Diversas restrições poderão estar presentes e há os que afirmam que os mercados são suficientemente imperfeitos para a administração das companhias considerar a política de dividendos em suas decisões (McCABE, 1979, p. 119). Neste contexto, a premissa do trabalho de MODIGLIANI \& MILLER não estaria sendo observada na prática.

LA PORTA et al. (2000, p. 3-9) estudaram as influências do sistema legal vigente, em vários países, na política de dividendos e concluíram que o comportamento dos investidores difere conforme a qualidade da proteção recebida. Os investidores que operam em países que lhes oferecem boa proteção legal utilizam-se deste instrumento para obter dividendos das empresas, especialmente quando as oportunidades de investimentos são escassas. Este mecanismo não funciona bem em todo e qualquer mercado porque o conteúdo das disposições legais e a eficácia com que são aplicadas difere de país para país. Os autores afirmaram que nos Estados Unidos e no Reino Unido as possibilidades dos acionistas minoritários serem ludibriados por gerentes e controladores é mais rara, sendo, portanto, classificada como boa a qualidade da proteção dada a estes acionistas. Nos demais países, embora haja um pouco de proteção, esta se apresenta de forma mais fraca, notadamente naqueles que são influenciados pelo direito civil francês.

No trabalho de LA PORTA et al. (2000, p. 9) empresas pertencentes a mercados que possuem regulamentos com políticas de dividendos obrigatórias, como por exemplo o Brasil, foram eliminadas da amostra. O foco dos autores foi estudar conflitos entre minoritários e controladores e gerentes e, para eles, o fato de as companhias situadas nestes países serem obrigadas a pagar dividendos, já denota uma preocupação em assegurar aos investidores estrangeiros sua participação nos resultados para encorajálos a adquirir ações. Na verdade, esta necessidade já denuncia o fato de que o sistema legal vigente não oferece boa proteção aos acionistas minoritários (LOPES, 2001, p. 143) e limita a total liberdade da administração para decidir o quanto vai reter dos lucros gerados.

No caso brasileiro, a Lei 6404/76, e posteriormente a Lei 10303/01, prevêem um mínimo de distribuição de dividendos de $25 \%$ do lucro ajustado. Além da influência da legislação societária, a partir de 1996 a política de distribuição de resultados também passou a ser influenciada pela legislação fiscal. A Lei 9.249/95 introduziu uma outra opção para as empresas remunerarem o capital próprio, por intermédio dos Juros Sobre Capital Próprio (JSCP), limitados à Taxa de Juros de Longo Prazo (TJLP). A partir de então, os $\mathrm{JSCP}^{12}$ passaram a ser tratados como despesa financeira sendo, diferentemente dos dividendos, dedutíveis para fins do cálculo do imposto de renda e contribuição social devida pela empresa.

BUENO (2000, p. 138) afirmou que as companhias brasileiras vêm se utilizando cada vez mais deste instrumento legal, provavelmente motivadas pela redução da carga tributária. A seguir tabela demonstrativa do número de empresas que pagaram dividendos e JSCP no período de 1997 a $2001^{13}$.

Número de empresas por ano

\begin{tabular}{lrrrrr}
\hline Ano & 1997 & 1998 & 1999 & 2000 & 2001 \\
JSCP & 48 & 53 & 68 & 17 \\
Dividendos & 177 & 199 & 179 & $30 \%$ \\
\% JSCP/Dividendos & $27 \%$ & $39 \%$ & $30 \%$ & $36 \%$ \\
\hline
\end{tabular}

${ }^{12}$ Maiores informações sobre a matéria poderão ser obtidas na Lei 9249/95, Lei 9430/96, art. 347 do RIR/99, Deliberação CVM 207/96, Instrução Normativa CVM 247/96. 
Além da legislação, seja ela fiscal ou societária, outros fenômenos podem influenciar a política de dividendos, como os apontados por ANDERSON (1997, p. 65). Neste estudo, os contratos de financiamento brasileiros, especialmente as debêntures, foram analisadas no período entre 1989 e 1993, quando o ambiente econômico e institucional era extremamente incerto e as debêntures eram usadas como fonte de captação. Segundo o autor, $68 \%$ das empresas da amostra que possuíam este tipo de contrato sofriam restrições de dividendos, especialmente quando as liquidações destes contratos estavam em atraso.

Estas restrições, legislações societárias e fiscais são fatores influenciadores das práticas de distribuição de dividendos e não são, por outro lado, uma exclusividade de um único mercado, como o brasileiro. A administração, dependendo do ambiente, não está completamente livre para estabelecer o nível de distribuição de dividendos que desejar. O tipo de financiamento utilizado, portanto, pode não ser irrelevante, para o valor da empresa, como afirmam MODIGLIANI \& MILLER.

\section{CONCLUSÃO}

A questão colocada - tendo em vista os argumentos teóricos e os estudos empíricos desenvolvidos até então, que importância pode-se atribuir à estrutura financeira das corporações, em especial, à política de dividendos? - foi abordada sob três enfoques: a hipótese da sinalização, a hipótese do agenciamento e a hipótese da preferência tributária e o efeito clientela. Foram apresentadas também algumas características presentes nos mercados que os diferenciam e que por este motivo, o comportamento da administração pode não ser homogêneo, quando está-se tratando de distribuição de dividendos.

Na primeira das três abordagens, a hipótese da sinalização, não se pode afirmar que os resultados fornecem apoio irrefutável ao conteúdo informacional dos dividendos, embora haja uma evidência favorável à idéia de que a administração usa a política de dividendos como um sinal. Isto pode ser verificado nos trabalhos de BAKER, FARRELLY e EDELMAN (1985) e de BAKER \& POWELL (1999), onde, apesar de haver um período de mais de 10 anos entre a primeira e a segunda publicação, os administradores, nas duas pesquisas, acreditam que os dividendos possam ser usados como um sinal. A crença dos administradores, verificada empiricamente, sugere que o efeito sinalização de dividendos é considerado pela administração quando esta fixa sua política de dividendos.

No trabalho empreendido por SHIRVANI \& WILBRATTE (1997), constatou-se que as empresas procuram estabelecer uma meta de longo prazo para o nível de distribuição de dividendos - consistente com LINTNER (apud SPERANZINI, 1994, p. 7). Este comportamento pode ser justificado pelo fato de que os dividendos são mais controláveis pelas empresas do que os lucros. As evidências indicaram que as entidades elevam mais prontamente os dividendos do que ao contrário. Quando estão abaixo da meta, o equilíbrio é restabelecido aumentando-os e, quando estão acima, da meta os aumentos vão sendo restringidos até que o equilíbrio seja atingido, sem que haja a utilização de cortes. Os administradores, portanto, se preocupam com os sinais contidos nos dividendos e procuram evitar os cortes.

$\mathrm{Na}$ abordagem da hipótese do agenciamento, os resultados também não são conclusivos. No entanto, parece haver apoio mais forte à idéia de que os dividendos são utilizados como redutores de conflitos, não sendo, portanto, irrelevantes. O trabalho de LA PORTA et al. (2000), por ser mais abrangente ao considerar 33 países em sua amostra, fornece apoio adicional a esta idéia.

$\mathrm{Na}$ abordagem da preferência tributária e efeito clientela, encontram-se os resultados mais mesclados, não sendo possível avaliar a sua real relevância. Por terem estudado as outras duas hipóteses em conjunto com o efeito clientela, vale mencionar os trabalhos de ABRUTYN \& TURNER (1990) e ZENG (2001). Ambos encontraram apoio mais fraco ao efeito clientela, comparativamente ao efeito informacional e à teoria do agenciamento.

Em relação à influência do ambiente sobre a política de dividendos, há evidências de que, em países que não possuem um nível adequado de acesso a informações e a recursos, pode haver preferência dos acionistas pelo recebimento ou não de 
dividendos. Até mesmo um tratamento diferenciado dado à distribuição de lucros, como os JSCP, podem estar relacionados ao comportamento da administração e dos investidores. Os trabalhos de ANDERSON (1999), ABREU (2002) e LA PORTA et al. (2000) sustentam tal concepção.

Nota-se, que a teoria de MODIGLIANI \& MILLER teve como base algumas premissas: mercado perfeito, racionalidade dos agentes do mercado e inexistência de custos de transação. Confirmar ou não empiricamente a teoria destes autores tem como "pano de fundo" uma realidade que, naquele momento específico do estudo, poderá ou não concordar com tais premissas. A maioria dos trabaIhos sobre o assunto tem sido realizada nos mercados mais desenvolvidos, como por exemplo o dos Estados Unidos, que, exatamente por ser mais desenvolvido, teoricamente, estaria mais próximo do "mundo" de MODIGLIANI \& MILLER. No entanto, cabe ressaltar que isto não é o mesmo que afirmar que o mercado americano é perfeito, mas apenas salientar que comparativamente a outros, como o emergente mercado brasileiro, existe uma supremacia do americano, em termos de desenvolvimento. Fica, portanto, a questão do quão perfeito e do quão consistente seria este mercado para se discutir a validade da teoria, em face dos resultados empíricos encontrados até então.

Por fim, apesar de não ser extensa, foi dada referência à pesquisa nacional já empreendida sobre a matéria, embora a abordagem adotada não tenha sido a comparativa, devido às diferenças, já apontadas, entre este e os demais mercados. Adicionalmente, os trabalhos existentes no Brasil sobre a matéria, presentes na literatura brasileira, são importantes e aguardam um maior número de evidências para aprofundar as discussões e contribuir ao desenvolvimento da pesquisa científica em finanças. Além das três abordagens tratadas neste trabalho, estudos sobre o relacionamento entre políticas de dividendos e políticas de investimentos também têm sido divulgados e são sugestões para investigações a serem efetuadas.

\section{REFERÊNCIAS BIBLIOGRÁFICAS}

ABREU, ARI FERREIRA de. As Preposições de Modigliani e Miller e a Tributação Brasileira. XXVI ENANPAD. Salvador: Set. 2002.

ABRUTYN, S.; TURNER, R. W. Taxes and firms' dividend policies: survey results. National Tax Journal. Columbus, Dec. 1999. Disponível: http://www.umi.com/proquest [capturado em 08 dez. 2001].

AHARONY, J.; SWARY, I. Quarterly dividend and earnings announcements and stockholders' returns: an empirical analysis. The Journal of Finance. New York, Mar. 1980. Disponível: http:// www.umi.com/proquest [capturado em 08 dez. 2001].

ANDERSON, C. W. Financial contracting uncer extreme uncertainty: an analysis of brazilian corporate debentures. Journal of Financial Economics. v. 51, p. 45-84, 1999.

BAKER, H. K., POWELL, G. E. How corporate managers view dividend policy. Quarterly Journal of Business and Economics. Lincoln, Spring 1999. Disponível: http://www.umi.com/proquest [capturado em 09 nov. 2001].

BAKER, H. K.; FARRELLY, G. E.; EDELMAN, R. B. A survey of management views on dividend policy. Financial Management. Tampa, Autumn 1985. Disponível: http://www.umi.com/proquest [capturado em 09 nov. 2001].
BRADLEY, M.; CAPOZZA, D. R.; SEGUIN, P. J. Dividend policy and cash-flow uncertainty. Real Estate Economic. Bloomington, Winter 1998. Disponível: http://www.umi.com/proquest [capturado em 25 nov. 2001].

BRASIL. Lei n. 6404, de 15 de dezembro de 1976. Disponível: http://www.planalto.gov.br/ [capturado em 08 jan. 2001].

BRASIL. Lei n. 9249, de 26 de dezembro de 1995. Disponível: http://www.receita.fazenda.gov.br/ [capturado em 08 jan. 2001].

BRASIL. Lei n. 9430, de 27 de dezembro de 1996. Disponível: http://www.receita.fazenda.gov.br/ [capturado em 08 jan. 2001].

BRASIL. Regulamento do Imposto de Renda - RIR 1999, de 26 de março de 1999. Disponível: http://www.receita.fazenda.gov.br/ [capturado em 08 jan. 2001].

BRASIL. Lei n. 10303, de 31 de outubro de 2001. Disponível: http://www.planalto.gov.br/ [capturado em 08 jan. 2003].

BROOK, Y.; CHARLTON JR., T.; HENDERSHOTT, R. J. Do firms use dividends to signal large future cash flow increases?. Financial Management. Tampa, Autumn. 1998. Disponível: http://www.umi.com/proquest [capturado em 10 jan. 2002]. 
BUENO, A. F. Análise empírica do dividend yeld das ações brasileiras. Dissertação (Mestrado em Ciências Contábeis). São Paulo: Departamento de Contabilidade e Atuária, Faculdade de Economia, Administração e Contabilidade, Universidade de São Paulo, 2000.

CHAPLINSKY, S.; SEYHUN, H. N. Dividend and taxes: evidence on tax-reduction strategies. The Journal of Business. Chicago, Apr. 1990. Disponível: http://www.umi.com/proquest [capturado em 10 jan. 2002].

CHRISTIE, W. G. Are dividend omissions trully the cruelest cut of all?. Journal of Financial and Quantitative Analysis. Seattle, Sep. 1994. Disponível: http://www.umi.com/proquest [capturado em 10 jan. 2002].

COMISSÃO DE VALORES MOBILIÁRIOS. Deliberação CVM n. 207 de 1996. [online]. Disponível: http://www.cvm.gov.br/ [capturado em 24 nov. 2000].

COMISSÃO DE VALORES MOBILIÁRIOS. Instrução Normativa CVM n. 247 de 1996. [online]. Disponível: http://www.cvm.gov.br/ [capturado em 24 nov. 2000].

DAMODARAN, Aswath. Avaliação de investimentos: ferramentas e técnicas para a determinação do valor de qualquer ativo. Traduzido por Bazán Tecnologia e Lingüística. Rio de Janeiro: Qualitymark, 1999.

DEWENTER, K. L.; WARTHER V. A. Dividends, asymmetric information, and agency conflicts: evidence from a comparison of the dividend policies of Japanese and U.S. firms. The Journal of Finance. Cambridge, Jun. 1998. Disponível: http:// www.umi.com/proquest [capturado em 12 jan. 2002].

DHALIWAL, D. S. et al. A test of the theory of tax clienteles for dividend policies. National Tax Journal. Washington, Jun. 1999. Disponível: http://www.umi.com/proquest [capturado em 09 nov. 2001].

DURAND, D. The cost of capital, corporation finance, and the theory of investiment: comment. The American Economic Review. v. 44, n.4, p.639-655, set. 1959. Disponível: http:// www.fucape/jstor [capturado em 12 mai. 2003].

ECONOMÁTICA Ltda. Banco de Dados [On Line], São Paulo, end. eletrônico: <www.economatica.com.br>, 2002.

FAMA, E. F. The empirical relationship between the dividend and investment decisions of firms. The American Economic Review. v. 64, n. 3, p. 305-318, jun. 1974.

GITMAN, L. J. Princípios de administração financeira: essencial. Traduzido da ${ }^{\mathrm{a}}$. ed. de Principles of Managerical Finace: Brief por Jorge Ritter. Porto Alegre: Bookman, 2001.

GONZÁLEZ, P. G. As mudanças nas políticas de dividendos e o mercado financeiro. Caderno de Estudos - Fundação Instituto de Pesquisas Contábeis, Atuariais e Financeiras. São Paulo, v. 10, n. 19, p. 70-81, set./dez. 1998.

GORDON, M. J. Optimal investiment and financing policy. The Journal of finance. v. 18, n.2, p.264-272, mai. 1963. Disponível: http://www.fucape/jstor [capturado em 12 mai. 2003].

HOLDER, M. E.; LANGREHR, F. W.; HEXTER, J. L. Dividend policy determinants: An investigation of the influences of stakeholder theory. Financial Management. Tampa, Autumn 1998. Disponível: http:// www.umi.com/proquest [capturado em 10 jan. 2002].
LA PORTA, R., et al. Agency problems and dividend policies. The Journal of Finance, v. LV, n. 1, p. 01-33, fev. 2000.

LAKONISHOK, J.; VERMAELEN, T. Tax-induced trading around ex-dividend days. Journal of Financial Economics. Amsterdam, Jul. 1986. Disponível: http://www.umi.com/proquest [capturado em 10 jan. 2002].

LEASE, R. C. et al. Some direct evidence on the dividend clientele phenomenon. The Journal of Finance. New York, Dec. 1978. Disponível: http://www.umi.com/proquest [capturado em 18 jan. 2002].

LINTNER, J. Distribution of incomes of corporations among dividends, retained earnings and taxes. The American Economic Review. v. 46, p.97-103, May. 1956. Disponível: http:// www.fucape/jstor [capturado em 27 mai. 2003].

LINTNER, J. Dividends, earnings, leverage, stock prices and the supply of capital to corporations. The Review Economics and Statistics. v. 44, n.3, p.243-269, ago. 1962. Disponível: http:/ /www.fucape/jstor [capturado em 12 mai. 2003].

LLOYD, W. P.; JAHERA, J. S.; PAGE, D. E. Agency costs and dividend payout ratios. Quarterly Journal of Business and Economics. Lincoln, Summer 1985. Disponível: http:// www.umi.com/proquest [capturado em 18 jan. 2002].

LONG, M. S.; MALITZ, I. B.; SEFCIK, S. E. An empirical examination of dividend policy following debt issues. Journal of Financial and Quantitative Analysis. Seattle, Mar. 1994. Disponível: http://www.umi.com/proquest [capturado em 18 jan. 2002].

LOPES, A. B. A relevância da informação contábil para o mercado de capitais: o Modelo de Ohlson aplicado à Bovespa. Tese (Doutorado em Ciências Contábeis). - São Paulo: Departamento de Contabilidade e Atuária, Faculdade de Economia, Administração e Contabilidade, Universidade de São Paulo, 2001.

MANUEL, T. A.; BROOKS, L. D.; SCHADLER, F. P. Common stock price effects of security issues conditioned by current earnings and dividend announcements. The Journal of Business. Chicago, Oct. 1993. Disponível: http://www.umi.com/proquest [capturado em 10 jan. 2002].

McCABE, G. M. The empirical relationship between investment and financing: a new look. Journal of Finance and Quantitative analysis. v. XIV, n. 1, p. 119-135, mar. 1979.

MERIKAS, A.; BRUTON, G. D.; VOZILIS, G. S. The theoretical relationship between the strategic objective of sales growth and the financial policy of the entrepreneurial firm. International Small Business Journal. London, Apr.-Jun. 1993. Disponível: http:// www.umi.com/proquest [capturado em 27 nov. 2001].

MICHAELY, R. Ex-dividend day stock price behavior: the case of the 1986 tax reform act. The Journal of Finance. New York, Jul. 1991. Disponível: http://www.umi.com/proquest [capturado em 11 jan. 2002].

MODIGLIANI, F. ; MILLER, M. H. The cost of capital, corporation finance and the theory of investment. The American Economic Review, v. XLVIII, n. 3, p. 261-297, Jun. 1958.

MODIGLIANI, F; MILLER, M. H. . Dividend policy, growth, and the valuation of shares. The Journal of Business, v. XXXIV, n. 4, p. 411-433, Oct. 1961. 
POTERBA, J. M. The market valuation of cash dividends: the citizens utilities case reconsidered. Journal of Financial Economics. Amsterdam, Mar. 1986. Disponível: http:// www.umi.com/proquest [capturado em 11 jan. 2002].

PROCIANOY, J. L. Conflitos de agência entre controladores e minoritários nas empresas brasileiras negociadas na bolsa de valores de São Paulo: evidências através do comportamento da política de dividendos após as modificações tributárias ocorridas entre 1988-1989. Tese (Doutorado em Ciências Contábeis). São Paulo: Departamento de Contabilidade e Atuária, Faculdade de Economia, Administração e Contabilidade, Universidade de São Paulo, 1994..

ROSS, S. A. et al. Administração financeira. Traduzido da $3^{\text {a. }}$ ed. de Corporate Finance por Antonio Zoratto Sanvicente. São Paulo: Atlas, 1995.

SANT, R., COWAN, A. R. Do dividend signal earnings? The case of omitted dividends. Journal of Banking \& Finance. Amsterdam, Dec. 1994. Disponível: http://www.umi.com/proquest [capturado em 10 jan. 2002].

SHIRVANI, H.; WILBRATTE, B. An empirical investigation of asymmetric behavior in corporate dividend policy. Economic Inquiry. Huntington Beach, Oct. 1997. Disponível: http:// www.umi.com/proquest [capturado em 25 jan. 2002].
SPERANZINI, M. M. Efeito da política de dividendos sobre o valor das ações no mercado brasileiro de capitais. Dissertação (Mestrado em Ciências Contábeis).- São Paulo: Departamento de Contabilidade e Atuária, Faculdade de Economia, Administração e Contabilidade, Universidade de São Paulo, 1994.

TITMAN, S. The effect of capital structure on a firm's liquidation decision. Journal of Financial Economics. Amsterdam, Mar. 1984. Disponível: http://www.umi.com/proquest [capturado em 25 jan. 2002].

VARIAN, H. R. Microeconomia: princípios básicos. Traduzido por Luciene Melo. Rio de Janeiro: Campus, 1994.

VOGT, S.C. The cash flow / investment relationship: evidence from U.S. manufacturing firms. Financial Management. Tampa, Summer 1994. Disponível: http://www.umi.com/proquest [capturado em 10 jan. 2002].

ZENG T. The determinants of dividend policy: Canadian evidence, 13, 2001, Rio de Janeiro. Anais da Thirteenth AsianPacific Conference on International Accounting Issues. Rio de Janeiro: FIPECAFI, 2001, p. 296-299. 